\title{
TRABALHO EM GRUPO NA EDUCAÇÃO A DISTÂNCIA: UM FOCO NA ORGANIZAÇÃO DAS RELAÇṌES E ESTRUTURA SOCIAL
}

\author{
Gislaine Rossetti M. Ferreira -PPGEDU/UFRGS - gislaineferreira@terra.com.br \\ Patricia A. Behar - PGIE/UFRGS - pbehar@terra.com.br \\ Fátima Weber Rosas - PGIE/UFRGS- fwrosas@gmail.com
}

\section{RESUMO}

Este artigo trata da análise das relações interpessoais de grupos no contexto virtual. Seu objetivo principal é refletir sobre a importância da estrutura social e sua influência nas interações entre pares, estabelecidas em um ambiente virtual de aprendizagem (AVA). É apresentado um levantamento teórico sobre a estrutura e o funcionamento de grupos no contexto educacional. A metodologia empregada foi um estudo de caso piloto. Para a coleta de dados, foram mapeadas as interações que ocorreram através das funcionalidades Fórum e Contatos do AVA ROODA em uma disciplina de graduação, ministrada a distância. Como resultado, apresenta-se a análise das relações interpessoais de grupos de alunos e um mapeamento destas em forma de gráfico através de uma funcionalidade desenvolvida para este ambiente, intitulada Mapa Social.

Palavras-chave: Educação a Distância, interações sociais, relações interpessoais.

\begin{abstract}
This article deals with the analysis of interpersonal relationships between groups in the virtual context. Its main objective is to reflect about the importance of the social structure and its influence on peer interactions in a virtual learning environment (VLE). A theoretical survey of the structure and the working groups in the educational context is shown. The methodology for this research was a pilot case study. The interactions mapped in Forum and Contacts intro the Education Platform called ROODA to collect the data in a subject taught at a distance learning. As a result, we present the analysis of interpersonal relationships of groups of students and a mapping of these as a graph through a feature developed for this environment, entitled Social Map.
\end{abstract}

Keywords: Distance Learning, social interactions, interpersonal relationships. 


\section{INTRODUÇÃO}

Com as constantes mudanças ocorridas no meio social e cultural, principalmente através das evoluções tecnológicas, torna-se primordial ao docente a constante atualização através de cursos de capacitação ou outros que o auxiliem a atuar na Sociedade da Informação. Devido ao crescente uso das Tecnologias de Informação e Comunicação (TIC), a maneira como docentes e discentes se relacionam vêm sofrendo modificações.

O ser humano é uma totalidade, envolvido por diversas dimensões: psíquica, social, espiritual, biológica e cognitiva (Moraes, 1997). No contexto educacional, sobretudo na Educação a Distância (EAD), tem ocorrido uma preocupação com a dimensão sócio-afetiva, além da cognitiva.

Conforme Piaget (1973), a aprendizagem acontece a partir da assimilação e da acomodação, gerando a equilibração. Contudo, para isso é necessário que o sujeito interaja com os objetos e com os outros sujeitos, em direção à construção do conhecimento. Desta forma, de acordo com com o autor, existem dois tipos de interação, uma entre sujeito e objeto e outra entre os sujeitos. Entende-se que, ao se estudar as interações sociais, é fundamental entender as ações dos sujeitos e suas repercussões. Ao interagir, o indivíduo agrega novos conceitos, outros valores e consecutivamente, obtém a possibilidade de questionar-se sobre suas convicções. A cada nova interação, os mesmos determinam como agir, adequando suas atitudes às necessidades da situação em que se encontram.

Observa-se que, entre as várias razões pelas quais os indivíduos se reúnem em grupos, a mais provável é a busca coletiva de se alcançar um objetivo. Verifica-se esta tendência nos grupos educacionais, principalmente quando os alunos têm que agir de forma coletiva, a fim de cumprir os desafios propostos pelo professor. Para tanto, tornase importante atentar, não somente na forma pela qual o processo social ajusta as contribuições individuais como resposta ao grupo, mas pelas contribuições particulares que influenciam este contexto até a finalização da tarefa (Davis, 1973).

Já Moreno (1972) estudou o desenvolvimento, a organização de grupos e a posição que cada indivíduo neles ocupa. Ao investigar as relações interpessoais de grupos, o autor constatou que, embora existam muitas, destaca-se duas principais: as relações de atração e repulsa. Embora este autor tenha centrado suas investigações na organização presencial física de grupos, entende-se que tais estudos possam contribuir para a formação de grupos em ambientes virtuais de aprendizagem (AVA).

Desta forma, este artigo apresenta na próxima seção alguns dos principais estudos sobre as relações interpessoais numa estrutura de grupos. Na seção três são discutidas a organização e os estádios na formação de grupos. Na quatro é explanado um mapeamento das interações sociais em AVA e para finalizar, a seção cinco traz as considerações finais. 


\section{RELAÇÕES INTERPESSOAIS EM ESTRUTURA DE GRUPOS}

Nunes et al. (2012), ao estudar maneiras de formar grupos eficientes para a EAD, atenta para os sistemas de recomendação ou de combinação social ${ }^{1}$. A autora menciona o Sistema de Combinação Social intitulado Group Recommender ${ }^{2}$. Esta ferramenta foi criada por Danilo Reinert e aperfeiçoada por Telles et. al. (2010). Seu foco é a formação de equipes de trabalho coordenadas por tutores em cursos a distância com um número muito grande de estudantes. Esse sistema tem a função de recomendar equipes de trabalho que levam em conta as similaridades entre os Traços de Personalidade dos alunos e as características do tutor. A autora ressalta a importância da composição de um grupo, já que esta influencia no seu desempenho.

Já Nass et.al. (1995) admite que as regras sociais nas interações humano-humano se aplicam igualmente nas interações humano-computador. Para o autor, a atração entre os sujeitos também é chamada de comunicação interpessoal. De forma semelhante às afirmações dos autores, Moreno (1972) sustenta que a habilidade de estruturar relações interpessoais e a aquisição de valores sociais depende das interações que se estabelecem no grupo de pares. Diversas investigações do autor sobre as afinidades entre os indivíduos com o grupo de pares, apontam para a existência de duas categorias distintas: os aceites e os não aceites. O grupo dos aceites pode ser claramente traduzido por índices elevados de impacto social e de uma forte preferência social. Estes são indícios que tais sujeitos podem ser mais competentes nas suas relações interpessoais do que os não aceites.

Para Moreno (2008), "o instrumento que mede o grau de organização dos grupos sociais é denominado teste sociométrico". A função deste teste é examinar as estruturas sociais, "medindo as atrações e repulsões que ocorrem entre as pessoas dentro de determinado grupo". Estudos deste tipo pertencem à Sociometria. Esta se ocupa da investigação quantitativa dos aspectos psicossociais de pequenos ou de grandes grupos. Sendo assim, a dicotomia "qualitativo" versus "quantitativo" é superada, já que um está contido no outro, sendo estudado como uma unidade. A Sociometria possui três pilares de referência: socius (companheiro), metrum (medida) e drama (ação). A partir destes resultam três campos de investigação: (1) sobre os grupos, (2) sobre a medição e (3) sobre a ação. Uma das técnicas desta ciência é a aplicação de testes sociométricos que permitem descobrir as semelhanças e as diferenças entre os indivíduos que compõem um grupo e é representado graficamente por uma rede chamada sociograma. Nesta são demonstradas as interações sociais, possibilitando a análise estrutural dessas. $\mathrm{O}$ autor também salienta a dificuldade de descrever o processo que atrai ou repele as pessoas entre si. Este transcurso ele denomina de Tele e trata-se de um processo que contém o fluxo de sentimentos que compõem o átomo e as redes sociais. (Moreno, 2008 p. 67).

$\mathrm{Na}$ próxima seção é apresentado o conceito de organização e estrutura de trabalhos em grupos.

\section{A ORGANIZAÇÃO E OS ESTÁDIOS NA FORMAÇÃO DE GRUPOS}

De acordo com afirmações de Moreno (1962), Minicucci (1975) sustenta que, quando o indivíduo se propõe a atingir uma meta, geralmente ele estabelece alguns 
parâmetros que serão desenvolvidos no decorrer do percurso. Ao determinar que o trabalho seja realizado em grupo, se evidencia o grau de equilíbrio deste sujeito através de suas ações. Torna-se então necessário que os membros compartilhem de valores comuns, aptidões e inibições individuais para melhor auxiliar seus colegas na realização eficaz da tarefa.

Para tanto, em um grupo bem constituído, todos são responsáveis no alcance das metas, pois existe uma colaboração mútua que se estabelece, a fim de facilitar a interação. Desta forma, os membros conseguem ultrapassar suas limitações e participam efetivamente do processo evolutivo do grupo (Minicucci, 1975).

Em concordância com Minicucci (1975), Paloff e Pratt (2015) entendem que o conhecimento da dinâmica de grupos online pode ajudar os professores e tutores a ajustar suas estratégias para lidar com problemas específicos tais como a pouca participação dos alunos ou dificuldades de relacionamento. Para os autores, o conhecimento de tais dinâmicas evita intervenções docentes desnecessárias ou até mesmo prejudiciais ao desenvolvimento de um grupo. Sendo assim, Paloff e Pratt (2015) investigam a natureza dos grupos online, seu desenvolvimento, teorias acerca de sua formação e como se aplicam na virtualidade.

Dentre as diversas teorias existentes, os autores são favoráveis ao modelo apontado por McClure (2005). Este autor propõe um modelo com sete estágios, conforme (Figura 1) para identificar o desenvolvimento estrutural de grupos. São eles: pré-formação, unidade, desunião, conflito-confronto, desarmonia, harmonia e execução. Ele destaca que há um declínio em direção ao conflito, sendo este o ápice inferior, seguindo a partir de então a uma ascensão rumo à execução.

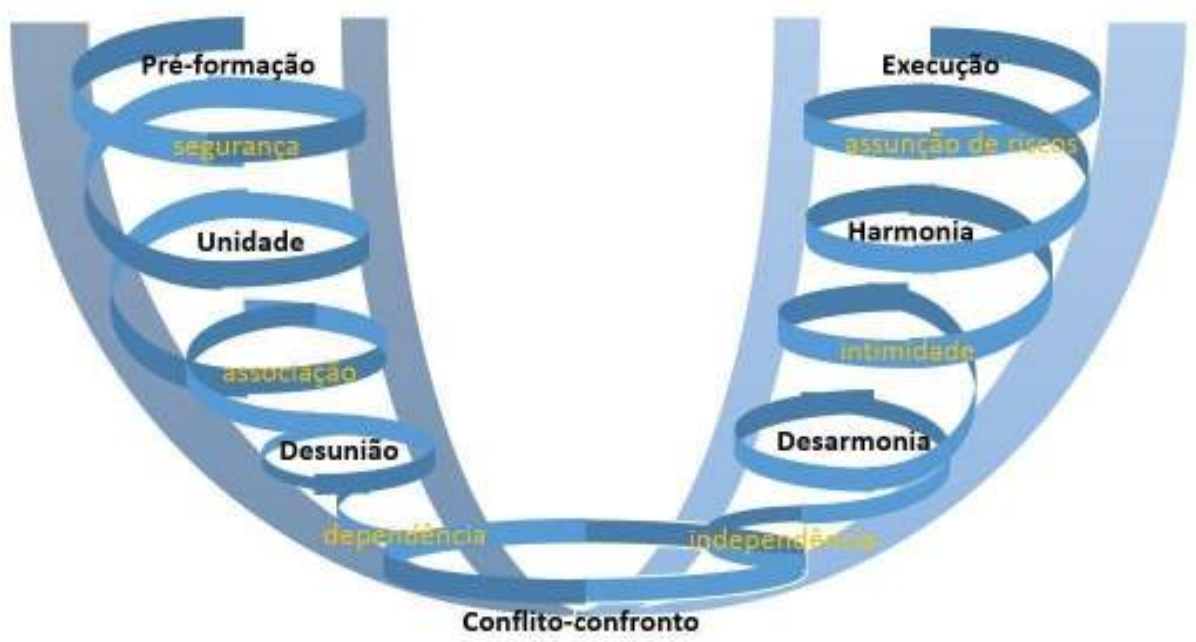

Figura 1 - Arco dos estádios de um grupo em espiral.

Fonte: Adaptação das autoras da figura 4 “Arc spiral” (McCLURE, 2005, p.80).

Conforme (Figura 1), são apresentados os estádios da esquerda para direita em forma de arco invertido. O lado direito, de baixo para cima apresenta movimento ascendente e retrata os membros do grupo como uma força coletiva emergente indo do Conflito-confronto à Execução. $\mathrm{O}$ arco é simétrico onde cada estádio de um lado é oposto ao estádio do outro lado. No lado esquerdo encontram-se as etapas em forma descendente (de cima para baixo) que os membros renunciam, partindo da Pré-formação 
ao Conflito-confronto. Já nas fases mostradas à direita do arco, os indivíduos recuperam o que renunciaram na esquerda.

$\mathrm{O}$ autor também sugere que o movimento através de estágios na descida é aleatório. Já na subida, os membros possuem controle voluntário de seu movimento. Portanto, o progresso através dos estádios é desigual, com avanços e recuos, porém, o movimento global do grupo é progressivo. As transições entre as fases ocorrem por saltos descontínuos e transformações não-lineares e desordenadas. Cada fase no arco representa um nível maior de organização. O sucesso em cada estádio é necessário para que o grupo alcance todo o seu potencial. A seguir cada fase é descrita detalhadamente.

(1) Pré-formação: Acontece quando o grupo está em formação. Nessa fase o líder do grupo organiza o grupo, determina a estrutura e localiza um ambiente apropriado. Ocorre então uma busca pela segurança.

(2) Unidade: $O$ sentimento predominante neste estádio é a ansiedade. Os membros do grupo estão preocupados com a sobrevivência, gerando fortes necessidades de dependência em relação ao líder, cuja expectativa é fornecer estrutura, ordem e limites.

(3) Desunião: A desunião é o primeiro estádio de conflito e retrata a crescente frustração e expressão de raiva indireta entre os membros do grupo.

(4) Conflito-confronto: Este estádio é uma fase intermediária entre a ordem e o caos em busca de um equilíbrio.

(5) Desarmonia: Representa o conflito entre os membros do grupo para chegar a um acordo apesar das diferenças e diversidades. Quando todos os membros investem esforços iguais em prol do grupo, do coletivo, o "nós" emerge.

(6) Harmonia: Este estádio é caracterizado por sentimentos de alívio e ocasionalmente de euforia onde ocorre profunda conexão com o outro. As diferenças são superadas e são estabelecidas normas sociais,

(7) Execução: Este é o estádio final do arco que caracteriza-se pela produtividade. Os relacionamentos são mais autênticos do que nas fases anteriores e seus membros compartilham honestidade e fornecem retorno direto uns aos outros. Os indivíduos também sentem-se mais seguros para a assunção de riscos.

Em relação à (Figura 1), McClure (2005) também acrescenta que em cada estágio do arco acontece um movimento de forças em espiral. Tais forças nascem da necessidade de satisfação e dos interesses individuais dos membros de um grupo. $\mathrm{O}$ autor representa essas necessidades em justaposição contra a força coletiva do grupo. São elas: segurança, associação, dependência, independência, intimidade e assunção de riscos. A energia amplificada pelo impulso de formar o coletivo e ao mesmo tempo a emersão das questões individuais impulsiona o grupo para prosseguir. Conforme este autor essa força centrífuga e centrípeta é que cria um movimento em espiral, simbolizando a transformação, a organização ou co-evolução entre as necessidades individuais numa auto-organização coletiva. Em cada estádio do desenvolvimento, uma das tarefas do grupo pode ser vista como uma satisfação da questão central. Na (Figura 1) observa-se os estádios em cor preta e as necessidades em cor laranja. Por exemplo, na fase Pré-formação e Unidade, a necessidade destacada é a segurança. No estádio Unidade e Desunião, a necessidade é a associação; na etapa da Desunião e Conflitoconfronto, destaca-se a dependência; no estádio Conflito-confronto e Desarmonia, a 
independência; na Desarmonia e Harmonia, a intimidade e na Harmonia e Execução, a assunção de riscos.

Diante das constatações de McClure (2005), Nass et. al.(1995), Minicucci (1975) e Moreno (1972), entende-se que é necessário a existência de regras para uma boa convivência social. McClure (2005) em seu modelo de sete estádios de uma estrutura de grupo aponta como $6^{\circ}$ e penúltimo estádio a Harmonia. Neste prevalece o respeito mútuo e o sentimento de pertencimento a um grupo.

Diante destas premissas, na próxima seção é discutido o mapeamento das interações sociais em AVA através de uma ferramenta intitulada Mapa Social e a estrutura de grupos nesses ambientes.

\section{MAPEAMENTO E ANÁLISE DAS INTERAÇÕES SOCIAIS DE ALUNOS EM UM AMBIENTE VIRTUAL DE APRENDIZAGEM}

Como dito anteriormente, Moreno (1972) ao estudar as relações em um grupo através da Sociometria, buscou compreender a dinâmica das relações interpessoais dentro dos grupos sociais. Para o autor, o padrão do universo social é invisível, mas os gráficos podem torná-lo visível. A partir dessas afirmações, entende-se que um sociograma deve representar da forma mais clara possível as relações básicas de um grupo social. Uma vez que a teoria de Moreno (1972) busca analisar as afinidades, indiferenças, atrações e repulsões entre os indivíduos de um grupo, essas informações devem ser expressadas de forma clara e concisa.

Com o objetivo de investigar as interações de grupos de alunos em cursos ou disciplinas a distância, está sendo realizada uma pesquisa junto ao Programa de PósGraduação em Educação da Universidade Federal do Rio grande do Sul.

Para este trabalho, é retratada a investigação de um estudo de caso piloto realizado em uma disciplina de graduação, no segundo semestre de 2014, ministrada na modalidade a distância. Somente duas aulas foram presenciais: a primeira para apresentação do ambiente ROODA; e a última para os relatos dos trabalhos desenvolvidos ao longo da disciplina. Esta investigação ocorreu com oito alunos da graduação, provenientes de diversas áreas. A metodologia consistiu na observação dos registros dos alunos no ambiente virtual de aprendizagem (AVA) Rede cOOperativaDe Aprendizagem $^{3}$ (ROODA) e na análise dos sociogramas gerados pela funcionalidade Mapa Social desse ambiente. O Mapa Social ${ }^{4}$ é uma funcionalidade desse AVA que apresenta em forma de sociograma as interações de alunos, tutores e professores nesse ambiente. O presente estudo utilizou esta funcionalidade juntamente com o Fórum e Contatos $^{5}$. Na primeira aula ocorreu a formação dos grupos, e no decorrer da disciplina foi realizado o acompanhamento das interações entre os mesmos. Ao se analisar o sociograma de tais interações, identificou-se neste período a ocorrência de três grupos, conforme (Figura 2). 


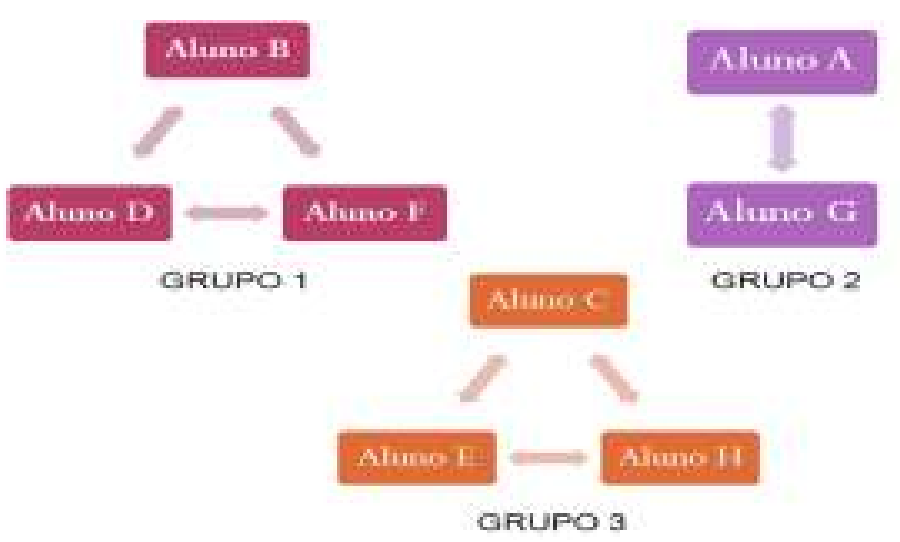

Figura 2 - Primeira Formação de Grupos

Fonte: as autoras (2014)

O Mapa Social demonstra as interações entre os membros da disciplina, como também a relação dos membros do grupo, conforme (Figura 3).

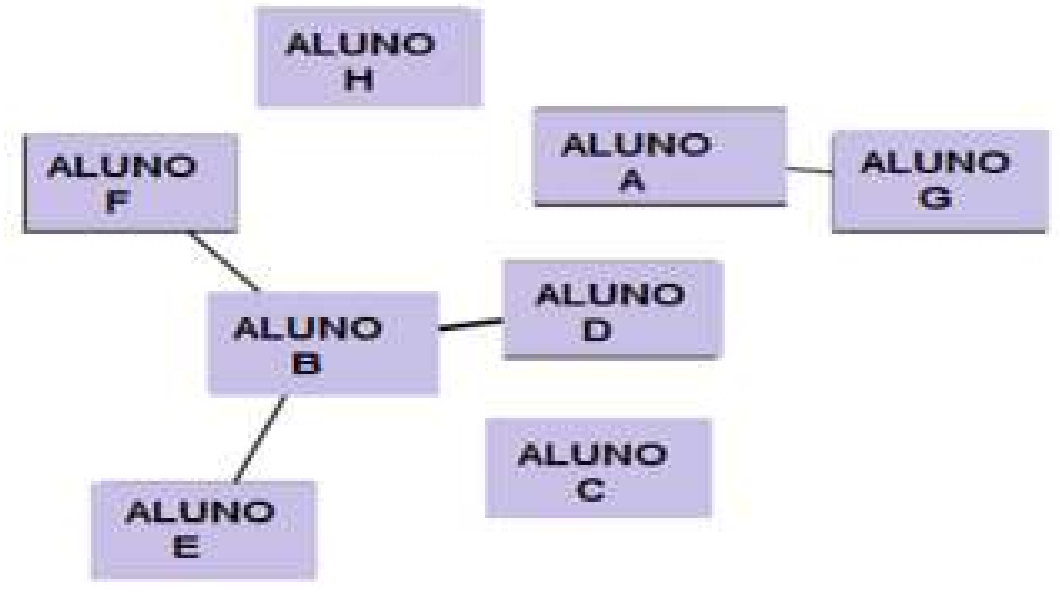

Figura 3 - Sociograma gerado pelo Mapa Social do AVA ROODA no início da disciplina

Fonte: Adaptado do AVA ROODA (2014)

Conforme (Figura 3), as linhas mais espessas significam que houve maior quantidade de interações (principalmente entre os alunos B-D, seguido dos alunos B-E na espessura). Já as mais delgadas demonstram menor número de interações entre os alunos (alunos: A-G e B-F). Para preservar a identidade dos alunos, seus nomes foram substituídos por letras do alfabeto. Assim pode-se observar, neste primeiro mapeamento no início da disciplina, que o aluno A interagiu com o B; o aluno F com B, B com D, F e $\mathrm{E}$ e os estudantes $\mathrm{H}$ e $\mathrm{C}$ não realizaram trocas sociais com nenhum colega.

Quanto aos grupos, verificou-se neste período inicial, que o grupo 1 (composto pelos estudantes B, D e F) e o grupo 2 (pelos alunos A e G) conforme apresentados na (Figura 2), interagiram entre si. Além da investigação desse sociograma, também foram analisadas as interações no Fórum e Contatos. Durante as primeiras semanas percebeuse indícios dos estádios de Pré-formação e Unidade descritos por McClure (2005). Entretanto, nas semanas seguintes, observou-se que o grupo 2 não conseguiu avançar, permanecendo nos primeiros estádios, isto é, não continuando além do Conflitoconfronto. Este fato foi evidenciado pela falta de integração e de entendimento entre 
seus membros. Os próprios integrantes deste grupo solicitaram uma reestruturação, alegando total falta de afinidade. É provável que este grupo não tenha superado os conflitos e sentimentos característicos do estádio de Desunião apontado por McClure (2005). Como o grupo não avançou nos estádios, houve a necessidade de intervenção da professora na reorganização da estrutura deste grupo. Para que nenhum aluno permanecesse ou viesse a tornar-se isolado, foi necessário interferir também na estrutura dos outros dois grupos. Dessa forma, devido à pouca quantidade de alunos, foi realizada uma nova divisão, resultando em dois grupos, conforme (Figura 4).

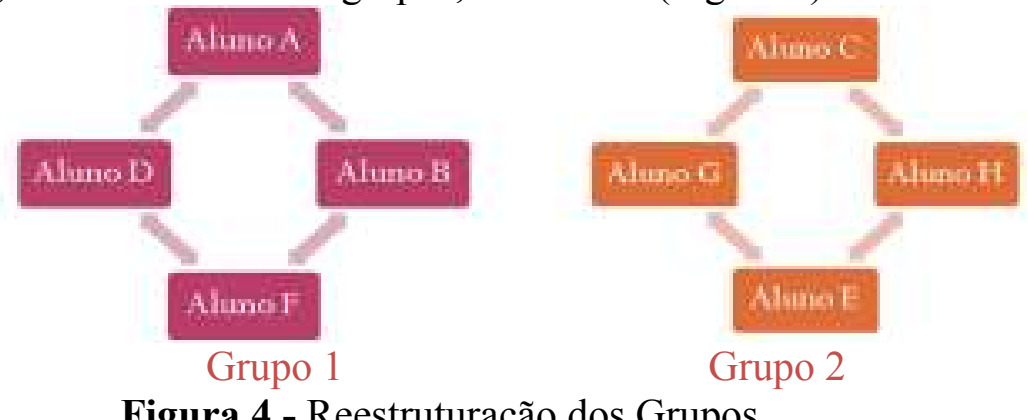

Figura 4 - Reestruturação dos Grupos

Fonte: As autoras (2014)

Após a reestruturação dos grupos, no final da disciplina, constatou-se que ocorreu um desconforto entre os membros, ocasionando uma diminuição das trocas sociais, conforme (Figura 5).

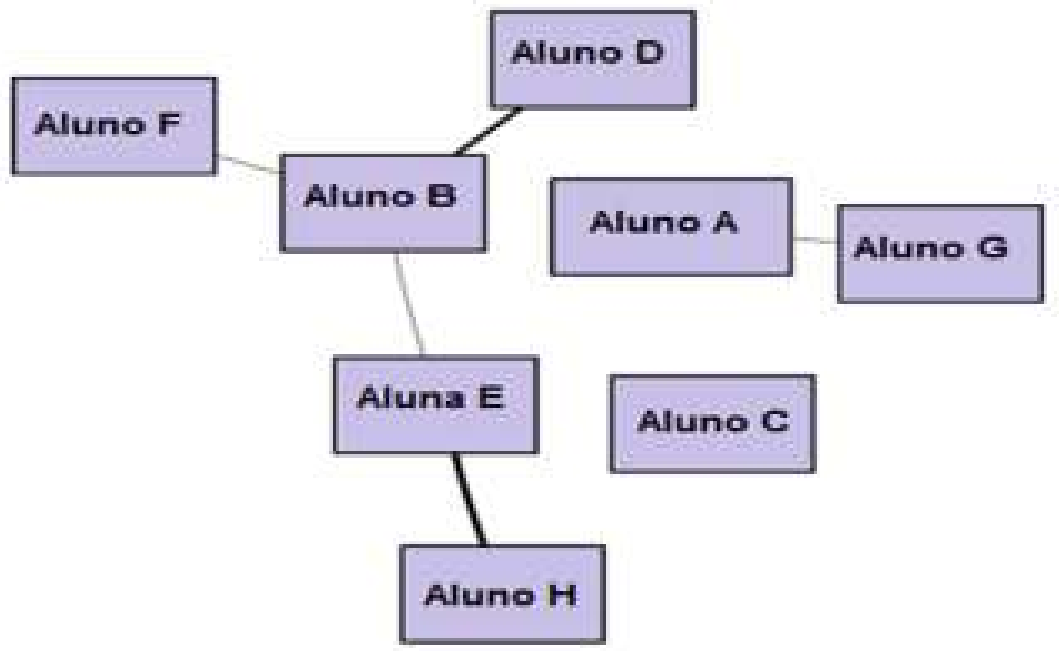

Figura 5 - Sociograma gerado pelo Mapa Social do AVA ROODA no final da disciplina.

Fonte: Adaptado do AVA ROODA (2014)

Como consequência dessa falta de interação, os grupos não atingiram a Harmonia e não chegaram à fase de Execução. Sendo assim, a tarefa foi realizada individualmente, ocasionando uma quebra no processo de grupo, conforme descreve Walvoord (1986). Entende-se que este fenômeno também é caracterizado como sendo um grupo de "não aceites", segundo Moreno (1972). Baseando-se na interação social regida pelas leis de atração e repulsa, o autor sustenta que cada indivíduo tem a liberdade de escolher como se situar em relação a seus colegas. Desta forma, para os 
docentes, conhecer como seus alunos se comportam em relação aos colegas pode auxiliar o seu trabalho. Uma vez detectado o funcionamento do grupo, é possível intervir na relação social existente no mesmo, a fim de conduzi-los a um melhor aproveitamento das dinâmicas propostas. No caso apresentado, houve esta tentativa de socializar todos os membros do grupo, mas apresentou-se a situação definida por Moreno (1994) de: Isolado, rejeitado, rejeitante - que ocorre quando o sujeito demonstra-se não somente sem escolhas, mas é, consecutivamente rejeitado pelos outros membros e, de forma recíproca, também rejeita todo o grupo.

A seguir são expostas as considerações finais.

\section{CONSIDERAÇÕES FINAIS}

Diversos autores, como (MORENO, 1972; 2008) e McCLURE, 2005) reconhecem a importância da socialização para uma boa convivência em grupo. Ao estudar os grupos, McClure (2005) ressalta que a Harmonia é necessária para se chegar ao estádio da Execução. Para Moreno (1972) o entendimento da estrutura e posição que cada indivíduo ocupa no grupo, determina relações sociais harmoniosas e com muita eficiência. Em conformidade com estes autores, acredita-se que a compreensão das relações interpessoais nos grupos, sua estrutura e a posição que os indivíduos nele ocupam, são importantes e contribuem para que o docente crie estratégias pedagógicas para resolver problemas de convívio social, tais como os descritos aqui anteriormente. Acredita-se em concordância com os autores, que a harmonia, a união, os entendimentos e a afinidade ou atração entre os membros de um grupo, são fatores determinantes para um bom desempenho das atividades propostas.

$\mathrm{Na}$ turma de alunos aqui descrita, a partir da análise do mapeamento, das interações no fórum e contatos do AVA, verificou-se que os grupos não conseguiram chegar à fase final de Execução, de acordo com os estádios propostos por McClure (2005). A visualização em forma de sociograma gerada pelo Mapa Social demonstrou a falta ou a presença quanto à quantidade de interação entre os alunos. Diante destas constatações, entende-se que o Mapa Social é um indicador das interações sociais e pode servir como uma ferramenta de apoio para diagnosticar relações interpessoais em um AVA. A partir de tais análises, entende-se que é possível ao professor/tutor criar estratégias pedagógicas que possam auxiliar a resolver tais conflitos na condução de atividades realizadas em grupo, principalmente na Educação a Distância.

\section{Notas de texto:}

1- Na computação, através dos Sistemas de Recomendação (SR), produtos, serviços ou conteúdos são recomendados a usuários que os buscam de acordo com suas necessidades e interesses. Quando essa busca é realizada com pessoas, esses sistemas também são chamados de Sistemas de Combinação Social. (NUNES, et.al. 2012).

2- < http://www.portaldainovacao.org/pi/detalhe/484>

3- <https://ead.ufrgs.br/rooda/>

4- O Mapa Social é uma ferramenta integrada ao AVA ROODA cuja função é mapear as relações interpessoais em forma de um sociograma. Este recurso foi desenvolvido a partir do Edital 19 da Secretaria de Educação a Distância (SEAD) da UFRGS.

5- Contatos é uma funcionalidade do ROODA para a troca de mensagens assíncronas. Tais mensagens são enviadas para o e-mail dos participantes. 


\section{REFERÊNCIAS BIBLIOGRÁFICAS}

DAVIS, J. H. Produção de grupo. São Paulo: Edgard Blucher e Ed. da Universidade de São Paulo.1973

MORAES, M. C. O paradigma educacional emergente. Campinas: Papirus, 1997.

McCLURE, Bud A. Putting a New Spin on Groups: The Science of Chaos. New Jersey. Psychology Press. $2^{\text {nd }}$ ed., 2005.

MORENO, Jacob Levi. Fundamentos de la sociometria. Buenos Aires: Editorial Paidós. 1972.

Psicodrama. 12.ed. São Paulo: Cultrix, 1997.

Psicodrama. São Paulo, Cultrix, 1978.

Psicoterapia de grupo e psicodrama. São Paulo: Editora Mestre Jou, 1974.

- Quem sobreviverá? Fundamentos da sociometria, psicoterapia de grupo e sociodrama. Goiânia: Dimensão, 1992, v. 1, 2 e 3. In: CUKIER, R. Palavras de Jacob Levy Moreno. São Paulo: Ágora, 2008.

NASS, Clifford; MOON, Youngme; FOGG, B.J.; REEVES, Byron and DRYER, D. Christopher. Can computer personalities be human personalities? In.: Int. J. HumanComputer Studies, vol.43, 1995. p.223-239.

NUNES, Maria Augusta S. Netto. Computação afetiva personalizando interfaces, interações e recomendações de produtos, serviços e pessoas em ambientes computacionais. In.: NUNES, Maria Augusta S.N.; OLIVEIRA, Adicinéia Aparecida de; ORDONEZ, Edward David Moreno (Org).Projetos e Pesquisas em Ciência da Computação no DCOMP/PROCC/UFS. 2012. p.113-149.

PALOFF, Rena M. e PRATT, Keith. Lições da sala de aula virtual. $2^{\text {a }}$ ed. Porto Alegre: Penso, 2015.

PIAGET, Jean. Estudos sociológicos, Rio de Janeiro: Forense, 1973.

Epistemologia genética. $2^{\text {a }}$ Edição. São Paulo: Martins Fonte, 2002. O Juízo Moral na Criança. Tradução de Elzon Lenardon. São Paulo:

Summus. $4^{\text {a }}$ edição. 1994.

Inteligencia y Afectividad. Tradução de Maria Sol Dorín. Buenos Aires:

Aique Grupo Editor, 2005.

WALVOORD, B. F Helping Students Write Well: A Guide for Teachers in All Disciplines. (2nd ed.) New York: Modern Language Association, 1986. 